\title{
Optimization of a hybrid tower for onshore wind turbines by Building Information Modeling and prefabrication techniques
}

\author{
Laura Alvarez-Anton, Manuel Koob, Joaquin Diaz and Jens Minnert
}

\begin{abstract}
Background: Nowadays wind energy is becoming increasingly significant in the planning, development and growth of new electricity supply systems. Special attention has been given to land-based turbines for ensuring the efficient economical operation of massive hubs rising $100 \mathrm{~m}$ above the ground, based on the idea that the bigger the turbine, the more complicated are the transportation and assembly processes.

Methods: A new design of a wind turbine has several advantages compared to conventional designs; one of these advantages lies in the use of prefabricated elements, which increases efficiency. The implementation of information technology as a complement to prefabrication techniques is a further aim of this research, which seeks to improve the overall performance of the project. Consequently, Building Information Modelling is suggested as the most suitable methodology for complementing off-site techniques and reaching higher efficiency by improving design, manufacture, transportation and assembly processes.

Results: This paper will present the research project "hybrid" tower for wind turbines" funded by the State of Hesse, Germany, which focuses on a new, efficient and economical design for high wind turbine towers. The new hybrid ${ }^{2}$ tower is composed of a concrete tower containing prefabricated concrete quarter-circle elements, steel beams and a steel tube tower on the top. The combination of concrete and steel beams improves the static and dynamic performance of the main supporting structure. With this new design, the weight of the concrete tower is estimated to decrease by $40 \%$ compared to a traditional full-concrete tower and, as a positive consequence, the cost of assembly (including assembly on site) is reduced.

Conclusions: Due to the energy revolution, a special focus is put on the development of renewable energies, especially wind power. The steadily increasing hub heights of wind turbines means that tower structures have to be more massive. The development of the hybrid ${ }^{2}$ tower by using Building Information Modeling and prefabrication techniques leads to an optimized performance and reduces transport and assembly costs.
\end{abstract}

\section{Background}

Shortly after the nuclear disaster in Fukushima in 2011, the German Federal Government decided to phase out all nuclear power plants and now plans to achieve this by 2022 . The aim is to shut down the plants gradually. For this reason, Germany puts special focus on the development of renewable energies like wind power, solar energy, hydroelectricity, biomass energy, etc. Of these renewable forms of energy, wind power has the greatest

\footnotetext{
* Correspondence: manuel.koob@bau.thm.de

* Correspondence: manuel.koob@bau.thm.de Gießen, Germany
}

potential for expansion. Countries like China, the U.S., Germany, Spain and India have a worldwide share of $72 \%$ of wind power production. Consequently, they are the most important markets. In relation to the other top 20 countries which have installed wind power systems, Germany is in second place in terms of surface area (right behind Denmark) with $99 \mathrm{~kW} / \mathrm{km}^{2}$. The first non-European country is China (ranked $16^{\text {th }}$ ) with $10 \mathrm{~kW} / \mathrm{km}^{2}$, followed by Japan and the U.S., each with $7 \mathrm{~kW} / \mathrm{km}^{2}$ (Fraunhofer IWES, 2013). In 2013, $24.7 \%$ of Germany's gross power consumption came from renewable energies. Wind power had the largest share with $33 \%$ onshore and $1 \%$ offshore wind turbines. Thus 
onshore wind turbines made the largest contribution to the overall power yield.

This paper briefly describes the development of existing onshore wind turbines. The Technische Hochschule Mittelhessen (University of Applied Sciences) in the State of Hesse in Germany has been doing research on a new tower for turbines of this type. The design of the new tower aims at reducing the requirement of construction materials and optimizing the time and cost of transportation and assembly. A visualization of the hybrid $^{2}$ tower is shown in Fig. 1. Moreover, the research goes a step further and looks for ways of generating synergies with existing methodologies. One such methodology is Building Information Modelling (BIM), which has several performance-enhancing features during the entire life cycle. Therefore this methodology has been taken into account regarding the development of the new hybrid ${ }^{2}$ tower.

\section{Research problem: Inefficient construction processes}

It is well known that the bigger the wind turbine is, the more complicated are the transportation and assembly processes. Moreover, another important concern of their on-site construction is the quality control and the efficiency of the construction processes. Therefore, the research problem definition will be focused on how to improve this situation, trying to combine a new design with the implementation of existing methodologies in the construction industry.

\section{General inefficiency problems in construction}

The rate of productivity improvement in the construction sector is significantly lower than in other industries. This is mainly due to certain inherent features, such as low rate of innovation, general inefficiency, lack of communication,

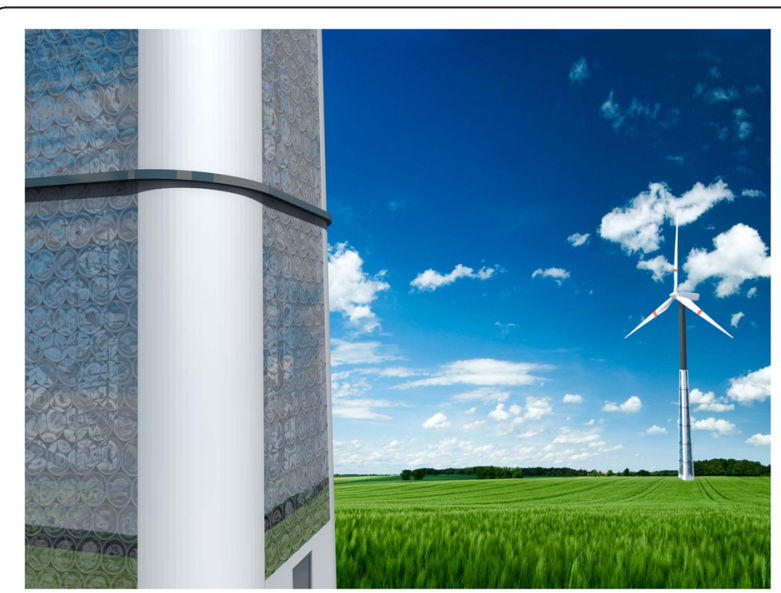

Fig. 1 Design of hybrid ${ }^{2}$ towers and overall fragmentation (McGraw Hill Construction, 2011).

Fragmentation in the construction sector between project phases and among stakeholders causes numerous conflicts, waste of resources, legal claims and overruns, all of which severely affect efficiency (Dawood et al. 2002). Construction projects involve a wide variety of stakeholders with different backgrounds and interests, and therefore fragmentation is often closely connected with inefficient communication and loss of information (Nawi et al. 2014), culminating in "Information silos" (Hu and Zhou, 2009). It is evident that there is a need for closer collaboration and improved communication between stakeholders throughout the different project phases (Mohd Nawi et al. 2014). This can be achieved by implementing information technology systems and enhancing interoperability to reduce information loss.

Moreover, the fact that each construction project is unique also means a loss in productivity compared to more industrialized sectors (Organisation for Economic Co-operation and Development, 2002). As a result, it is necessary today, especially in the face of increased competition and greater environment demands, that the construction sector develops a more industrialized approach whereby prefabrication practices enhance efficiency (Nawari, 2012).

\section{Inefficiency in the construction process of onshore wind turbines}

For the efficient operation of a wind turbine, an average wind speed of 5 to $6 \mathrm{~m} / \mathrm{s}$ is required. The energy of the wind flow thereby changes with the third power of wind velocity. Accordingly, the tower height of a wind turbine is dependent on location and its hub height ultimately determines economic efficiency. Therefore a number of wind turbine manufacturers create different combinations of rotor diameters and hub heights to offer the optimal solution for each location. For non-coastal regions, the following proportionality can be applied as a rule of thumb: the yield increases by up to 1 percent per meter of hub height of the wind turbine. For that reason, hub heights of over $100 \mathrm{~m}$ are often suitable for inland sites. Increasing hub height is an essential factor in the future of wind power production. This can already be seen in the case of newly installed wind turbines in Germany. In order to reach the desired hub height, the structure of the tower is of particular importance. Furthermore, the tower is the largest and heaviest component of a wind turbine and makes up 20 to $25 \%$ of the total costs, including assembly and transportation (Gasch and Twele, 2007).

The structure of new wind turbines continues to develop in the direction of prefabrication of individual 
components as well as complete tower sections. The rapid development of such wind turbines in recent years has received political support. For higher wind turbines, self-supporting towers are mainly used. They can be built in various forms of structures. In addition to the hub height, natural frequency is also an important criterion regarding the efficiency of a wind turbine. The crucial objective for the manufacturer is to achieve the required tower height and the corresponding stiffness with low construction costs. The most popular tower types according to (Hau, 2014) are lattice towers, steel tube towers, concrete towers and hybrid towers.

Lattice towers are used for greater hub heights. Because of their effective transmittance, lattice towers can easily be integrated into the surroundings. In addition, they are more economical in terms of material and weight. However, the manufacture and maintenance of these towers is very labor-intensive. Due to the high labor costs in Germany, lattice towers are becoming less common.

Steel tube towers have a total height of 60 to $100 \mathrm{~m}$ and are used for a large number of wind turbines. Such towers usually consist of an upwards conically tapering cross-section. One can say: the higher the tower, the wider its base. Due to problems regarding transportability and the limited thickness of the plates, the tower height is limited to $100 \mathrm{~m}$. German road bridges have a vertical clearance of $4.0 \mathrm{~m}$ and thus limit the diameter of the lower tower sections when it is delivered in one piece. Composite in-situ steel towers did not become popular because of the high welding and assembly costs.

There are different forms of concrete towers (Hau, 2014). Centrifugal concrete towers can be produced more cheaply, but have high transportation and assembly costs. In-situ concrete towers are easier to transport and assemble. They can be constructed directly on site by means of sliding or climbing formwork. However, the main problem with in-situ construction is to control the quality of the concrete casting. In bad weather conditions, such as cold temperatures and strong winds, the assembly is time-consuming and becomes more costly with increasing altitude.

In order to overcome these difficulties, a production method based on precast concrete elements was introduced. It is possible to prefabricate the individual segments cost-effectively and with a high level of quality. The prefabricated structure optimizes transport and assembly and the tower can be adapted to the local conditions. The aim is to manufacture the components as far as possible in serial production without alterations. This leads to a significant reduction in formwork and lowers the costs per segment. After the precast concrete parts have been assembled on site, they are suppressed by means of vertical prestressing bars across the entire height to protect the concrete from tensile stress. Towers with bigger contact areas can be built more efficiently with the help of this construction method. An important advantage compared to the in-situ concrete towers is the easier deconstruction of prefabricated components after the wind turbine has reached the end of its service life.

A combination of concrete towers and steel tube towers has been used increasingly during the last few years. The so-called hybrid towers consist of a concrete tower with precast elements in the lower part and an attached steel tube tower in the upper part. Larger hub heights of over $100 \mathrm{~m}$ can be manufactured at comparably low cost using this variant. Furthermore, by varying the height of the concrete and steel tube tower, it is possible to influence the natural frequency, thus improving operating efficiency.

\section{Methods and innovative solution}

The research problem aim of this paper consists in addressing the complex processes involved in the transportation and assembly of wind turbine towers. A new and more efficient and economical design supported by industrialized and computerized processes could be an appropriate solution.

\section{Development of tower design Structural design}

Prefabricated hybrid towers consisting of a prestressed reinforced concrete tower and an attached steel tube tower offer considerable potential for improvement. The development of hybrid towers is quite recent, which is why there is still a great need for further advancement in this field. The lower part of the concrete has considerable self-weight. This has to be optimized with regard to material requirements and assembly. Furthermore, the composite precast concrete towers are built of vertical and horizontal joints, which are prone to damage under dynamic loads. One idea is to minimize these problems with the development of a new structure for hybrid towers made of precast reinforced concrete. A framework would replace part of the concrete section, thus creating an open tower construction. With the combination of precast concrete and framework, the concrete tower itself becomes a hybrid which is completed by an attached steel tube tower. The result is a hybrid tower in a double sense, the so-called hybrid ${ }^{2}$ tower.

The new hybrid ${ }^{2}$ towers consist of four prefabricated quarter-circle-shaped concrete elements in the crosssection which are connected by a framework. A sideview of the concrete tower as well as a lower and upper cross-section are shown in Fig. 2. The quarter-circleshaped elements are $10 \mathrm{~m}$ high and have an identical construction at every level. Thus it is possible to produce these elements in series with the same formwork in precasting factories. The weight of one single 


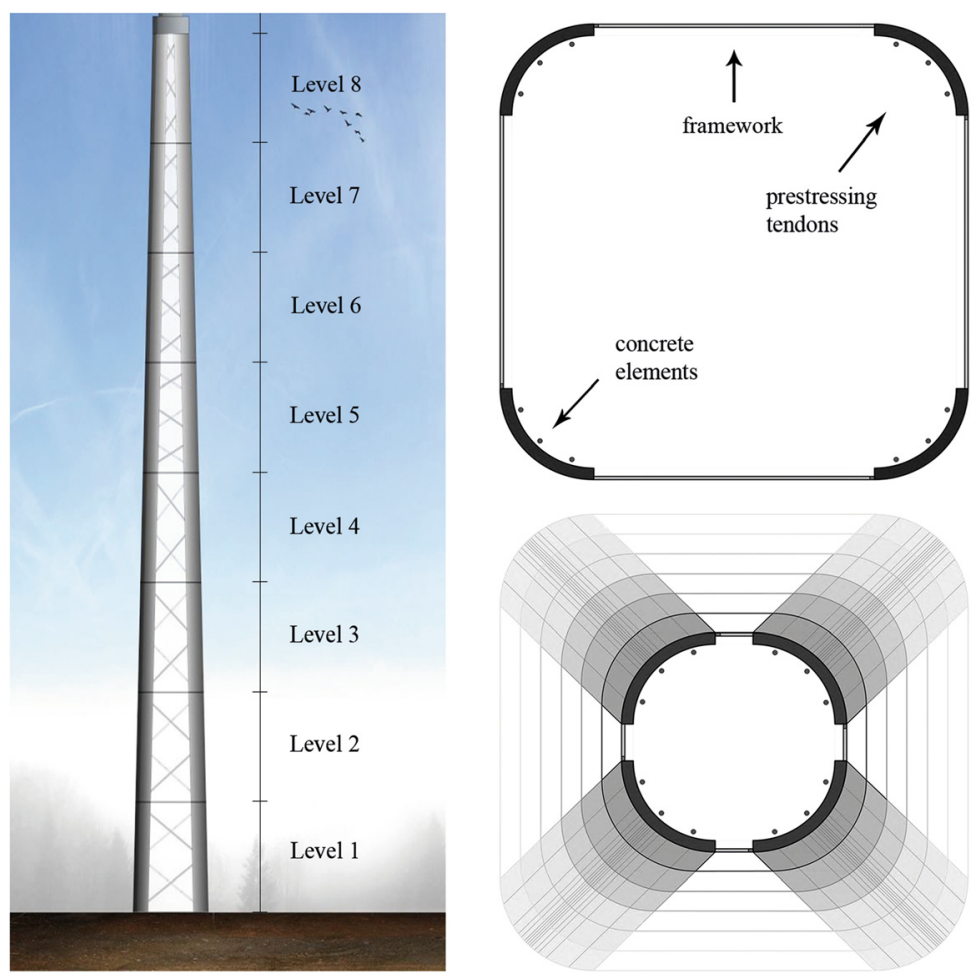

Fig. 2 Side-view of the tower (left); lower and upper cross-sections of the tower (right)

element is less than $20 \mathrm{t}$. This means that they can be delivered to the building site without the need for special transports, which are inevitably expensive.

The desired hub height determines the horizontal distance between each concrete element. It should be borne in mind that the higher the tower, the greater the base needs to be. The framework connects the concrete elements, thus the distances between the elements are variable. Moreover, the concrete elements are constructed with a slight inclination which means that the respective distance and the framework taper upwards. For example, a hub height of $145 \mathrm{~m}$, which is common in hybrid towers in Germany, requires a base of $10 \times 10 \mathrm{~m}$. Towers of this dimension are made up of a concrete tower including foundations, an adapter ring with a height of $85 \mathrm{~m}$ and the attached steel tube tower with a height of $60 \mathrm{~m}$. Due to the modular construction concept of the hybrid ${ }^{2}$ tower and the fact that each level has a height of $10 \mathrm{~m}$, it is not a problem to vary individual heights. Because of the taper, the conventional steel tower, which has a diameter of about $4 \mathrm{~m}$, can be attached flush to the concrete tower with the help of the adapter ring.

Different materials have been tested with regard to the framework construction. The best option is to employ commercial steel profiles, whereby trussed steel beams are used to connect the precast elements. This framework gives the hybrid ${ }^{2}$ tower a lower weight and an open structure. In addition, the trussed beams have a strutting function. All in all, the beams are an essential component of the tower. They absorb tensile and compressive forces and transmit them to the next precast concrete corner element. The steel framework and the precast concrete elements are connected by grouting, which is a well-established procedure in precast and composite constructions. For this purpose, there are gaps in the precast elements where the trussed beams can be put in position, adjusted and grouted during the construction progress.

Inside the tower there are vertical external prestressing steel tendons, which set the concrete elements under compressive stress and thus counter the occurring tensile forces. The prestressing tendons are anchored in the foundations and the adapter ring. The adapter ring is an important link between the concrete tower and the steel tube tower.

The open structure of the framework offers further creative possibilities. In the standard version of the open framework, the tower is transmittance and can be easily integrated into the landscape. The open areas between the concrete elements may be used to enhance the overall appearance of the tower, e.g. illuminated billboards could provide space for advertising. Alternatively, the 
intermediate gaps can be filled with various materials (e.g. film, trapezoidal sheet metal) to create a uniform surface.

\section{Joints of the precast concrete elements}

Pre-constructed hybrid towers consist of a complete concrete cross-section in the lower part. Especially in the case of precast constructions, horizontal and vertical joints cannot be avoided. A concrete butt joint without mortar can only be made with complex and expensive equipment. Grouting the joints is considered to be a better alternative. However, post-grouting the vertical joints becomes difficult in bad weather conditions and at high altitudes, and often faults appear if the joint is not filled correctly. At a later stage, serious problems may arise with respect to durability and density, and efficient force transmission cannot be guaranteed, a situation which is critical regarding dynamic loads. The hybrid ${ }^{2}$ tower has no vertical joints if a framework is used, a fact which improves the structure as a whole.

Horizontal joints are less problematic than vertical joints. The vertical prestressed tendons are adapted to avoid tensile stress in the horizontal joint under dynamic load, and a gap only appears in the joint between two overlapping concrete elements in the ultimate limit state. The prestressed steel tendons absorb the resulting tensile forces. Depending on the weather, huge problems may occur when using grout. Especially in colder regions, grout cannot be used without first applying special measures. Alternative connections (e.g. elastomer supports) still need to be researched.

\section{Foundations and adapter ring}

The foundations of prestressed concrete towers for wind turbines have a circular ring shape and are built with in-situ concrete. In the middle opening of the foundations there is a place where the prestressed steel tendons are anchored. The prestressing jack has to be set in this so-called cellar to apply vertical prestressing to the concrete tower. The required working space is quite large and the tendons must be anchored in the foundations. For this reason, foundations for wind turbines with a height of $4 \mathrm{~m}$ are not uncommon. The elaborate formwork and time-consuming concreting make the foundations a significant cost factor. Therefore it is necessary to reduce the material requirement for the foundations so as to build them as economically as possible.

In order to absorb the prestressed steel tendons on the upper side of the concrete tower, an adapter ring is used. This ring also has the function to transfer the forces from the steel tube tower to the concrete tower. It is made of reinforced concrete and often has a weight of more than $50 \mathrm{t}$. However, there is room for improvement in this area.

\section{Assembling the hybrid ${ }^{2}$ tower}

The first step in assembling the tower is to build the foundations, including the cellar and the anchor for the prestressing steel tendons. To speed up the process, the concrete corner elements and the trussed beams should be delivered to the building site in good time. As mentioned above, the formwork used in the precast factories is usually the same each time, a factor which optimizes pre-production and guarantees punctual delivery. The first corner elements are placed on the foundations and aligned on grout. In the next step, the trussed beams are put in place and secured in the right position. During assembly, a steel ring stabilizes the quarter-circle-shaped concrete corner elements and ensures accurate installation of the trussed beams. The gaps in the precast elements are filled. The first level of the tower, consisting of four corner elements and the trussed beams, is now complete.

Pre-assembly of the following levels also takes place on the ground. Mobile foundations made up of prefabricated concrete plates are arranged next to the actual tower. Pre-assembly of the next levels is carried out in the same way as described for the first level. In cold regions, this can also be done under a special cover, which allows temperature-independent assembly and provides optimum conditions for grouting. Each level of the hybrid $^{2}$ tower is lifted into position, placed on grout and aligned by a hydraulic device. The same procedure is repeated as often as necessary. The upper end of the hybrid ${ }^{2}$ tower is built on the adapter ring. This ring is also positioned and aligned on grout. After completion of the concrete tower, the external prestressed steel tendons are installed and reach from the foundations to the adapter ring. The prestressing cables have no anchor points on the reinforced concrete corner elements so as to avoid unbalanced forces. After the necessary prestressing force for the concrete tower has been applied, installation of the steel tube tower can begin. This is done in the same way as with assembled wind turbines.

For assembly of the hybrid ${ }^{2}$ towers it is necessary to use a mobile truck crane rather than a crawler crane because of weight optimization. (A comparison of these two cranes is shown in Fig. 3.) This has significant advantages when choosing the location of the wind turbine and also helps to reduce costs considerably. A crawler crane has to be brought to the construction area with the help of special transports and is assembled on site. In contrast, the mobile truck crane is self-propelled and because it consists of much less equipment, it can be delivered with normal trucks. Additionally, there is less effort involved in securing access to the building site, 


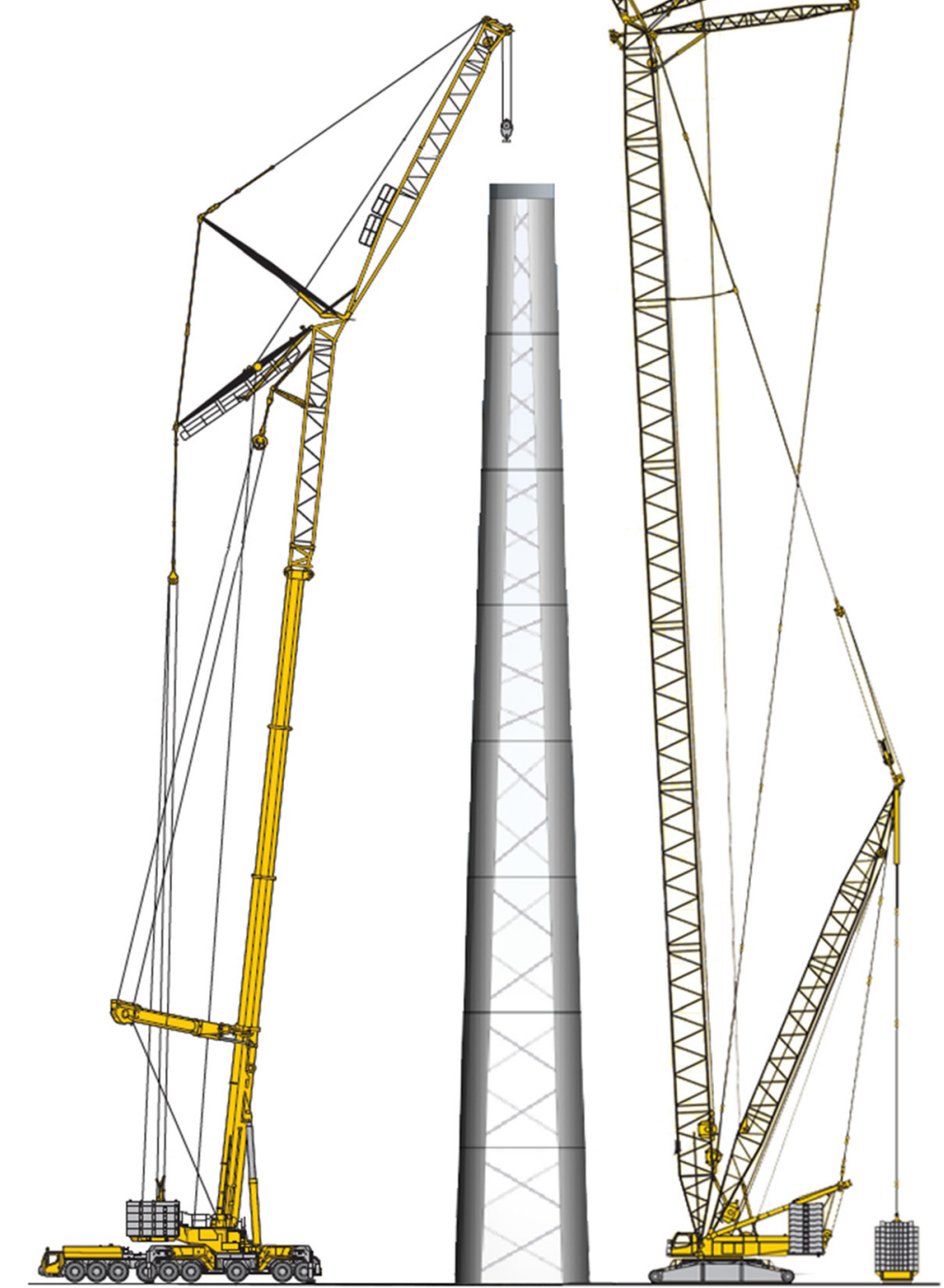

Fig. 3 Comparison of a mobile crane and a crawler crane for a wind turbine (Liebherr Werk, 2014)

which is important since the large wind turbines are erected mainly in rural areas or forests. A hybrid ${ }^{2}$ tower with 8 levels can be assembled in five days. The costs of using a crawler crane for a complete concrete cross-section amount to $100,000 €$, including assembly and dismantling, but not including personal costs. In contrast, the costs of using a mobile crane are less than half this sum. Furthermore, considerable costs arise if the assembly work is interrupted because of bad weather conditions or high wind speeds. On average, 10 days are lost during the assembly of one wind turbine. The rate per lost day for the mobile truck crane is only about $65 \%$ of that of the crawler crane. In addition, the smaller mobile crane can be used for lifting even at high wind speeds, and thus downtimes are minimized. All this shows that there are many complications with regard to the construction and operation of wind turbines, and costs can increase significantly. With the help of Building Information Modelling methodology during planning, assembly and operation, the participation of all stakeholders can be optimized. 
Performance improvement techniques and methodologies: Prefabrication and Building Information Modelling

Among the methodologies and processes which are available for improving the efficiency and productivity of a given construction project, Building Information Modelling (BIM), prefabrication, modularization and off-site techniques must be highlighted. An example of this can be found in a study carried out by a committee of experts of the National Research Council (NRC) in 2008 to define the existing possibilities of improving the productivity and competitiveness of the construction industry in the United States. In this study, both BIM and off-site techniques were classified among the five key measures with a capacity to enhance overall performance by improving quality, time and cost efficiency, and sustainability. Moreover, the study underlined the fact that efficient implementation of BIM methodology and the use of off-site manufactured components will lead to a change in the way of working in the industry, mainly based on open collaboration (National Research Council, 2009).

The aim of the research is to present a new design for wind turbine towers at a time when attention is focused on breaking up information silos and improving project performance by transforming standard construction processes into more industrialized ones.

\section{Prefabrication}

Highly industrialized sectors, such as computer or automotive manufacturing, have reached a level of automation that has significantly increased their productivity and efficiency. This has led to discussions as to why the construction industry has not implemented techniques and methodologies aimed at enhancing performance as successfully as other industrialized sectors have done. Prefabrication is one of the techniques which could bring about higher levels of automation by creating synergies with BIM capabilities.

Prefabrication and modularization processes and technologies are based on the fabrication and assembly of the elements "off-site" and their subsequent transportation to and installation at the construction site in question. These techniques are associated with considerable time and cost reductions and noticeable quality improvements due to their efficient use of resources (National Research Council, 2009).

The benefits of prefabrication and modular construction have been highlighted in different studies. In 2011 McGraw Hill Construction focused on improved productivity as being one of the main advantages and emphasized the following aspects: shortening of overall project schedule, reduction in costs and wastage (especially with respect to the construction site itself) and higher level of on-site safety (McGraw Hill Construction, 2011).

Reducing on-site construction activities leads to timesaving and consequently to cost-saving. Prefabrication enables on-site work to be done at the same time as other tasks are being carried out off-site. It also cuts the project-related budget in a number of ways: not so many expensive on-site tasks, fewer on-site resources, less risk of paying overtime, elimination of unexpected costs (McGraw Hill Construction, 2011). Moreover, prefabrication offers more quality and greater reliability since controls are more effective under off-site conditions and there is generally a higher level of precision than is the case with on-site procedures (National Research Council, 2009). Finally, there is also a substantial decrease in wastage (i.e. less on-site debris), which means a benefit for the environment as well (McGraw Hill Construction, 2011).

The study conducted by McGraw Hill Construction highlighted three further factors that are contributing to the increased use of prefabrication in the construction industry: lean construction (thanks to higher productivity), BIM (which is starting to be more widely implemented), and green construction (which is growing rapidly in importance). In fact, the contribution made be BIM methodology towards improving the productivity of prefabrication has been highlighted as an incentive for spreading the use of this technique in the construction industry as a whole (McGraw Hill Construction, 2011).

\section{Building Information Modelling}

The implementation of information technologies is currently playing an important role in the construction industry. However, compared to other industries such as automotive or aircraft manufacturing, construction still has a long way to go in this respect. Extensive application of information technologies such as Building Information Modelling (BIM) would support the efficient implementation of industrial processes, e.g. prefabrication and off-site construction (Nawari, 2012).

The performance of a project is invariably enhanced by improving interoperability, such as can be achieved by implementing information technologies like BIM. The main advantages of this methodology include: management of information among stakeholders and during all phases, visualization, scheduling, cost estimation, and materials tracking. BIM also helps to optimize decisionmaking processes. In addition, the comprehensive data management system of BIM enhances data accuracy and reduces unnecessary data reentry tasks. By offering an automatic answer to changes in design, BIM enables designers and engineers to observe the immediate consequences of their actions. Errors in design are easily identified whereas errors which originate from the 
inconsistency of 2D drawings are eliminated thanks to the 3D model. A multidisciplinary assessment of the model can be developed and future defects and errors eliminated before the construction phase. Finally, BIM supports lifecycle management and has important post-construction benefits related to management and operation processes; this is due to fact that the model acts as the main source of information and includes all design and as-built information (Eastman et al. 2011). It should be remembered that effective BIM implementation requires collaboration among stakeholders as well as integrated processes, but this will in itself reduce fragmentation in the industry (National Research Council, 2009).

\section{Results and Discussion}

\section{Benefits of the new hybrid tower}

The main advantage of the new structure used for the hybrid $^{2}$ tower is cost-saving, especially with regard to transportation and assembly. The cost-saving process actually starts in the precast factories during production of identically constructed concrete elements for the entire tower. Only one formwork is necessary for precasting all the elements, which leads to a reduction in production costs. The inclination of the tower is made possible by the variation in length of the truss beams. These beams can be produced accurately in the factories and are easy to deliver to the construction site due to their low selfweight. Based on this principle, it is possible to construct towers of different heights by varying the number of levels. After the elements have been delivered with conventional trucks to the construction site, each level is pre-assembled on the ground. The self-weight a hybrid ${ }^{2}$ tower is reduced by the use of trussed beams and the resultant open structure; thus smaller cranes are used for on-site construction than is the case with full-concrete towers. When each level of the hybrid ${ }^{2}$ tower has been pre-assembled, it is placed on top of another one and the joints are grouted. The above mentioned procedure leads to a reduction in the time needed for construction and assembly. In summary, this construction principle improves both static and dynamic performance as well as optimizing transportation and assembly processes. Building Information Modelling makes a significant contribution to the development, planning and assembly of the hybrid ${ }^{2}$ tower.

\section{Benefits of combining Building Information Modelling methodology and prefabrication processes}

Construction industry is currently characterized by the growing implementation of industrialization and computerization processes, this leads to the growing presence of prefabrication and Building Information Modelling presence. Their advantages are noticeable. The combination of BIM methodology and prefabrication processes generates important synergies. On the one hand, BIM provides greater reliability and precision and, on the other hand, the materials and manufacturing processes involved in prefabrication gain significantly in quality. All in all, the productivity of construction projects is increased (McGraw Hill Construction, 2011). Moreover, increasing implementation of BIM methodology may well boost prefabrication as a whole. With the help of BIM methodology, it is possible to create model-driven prefabrication where off-site processes can be developed and handed over to the manufacturers (McGraw Hill Construction, 2011).

Thanks to its high level of accuracy, BIM functions as a source of information for fabrication and construction processes. These processes are facilitated by the model's $3 \mathrm{D}$ definition of the elements. The practice is currently widespread in the steel industry and has also been successfully applied to precast elements. The model contains all the details needed for the fabrication processes and enables more complex elements to be constructed off site than was possible with 2D techniques (Eastman et al. 2011).

The fact that successful off-site production is based on effective information exchange between stakeholders calls for an efficient information management system like BIM. This system has the capacity to select the required data at the right moment for each stakeholder. Prefabrication processes need well-functioning coordination and collaboration among the stakeholders, so that high quality products reach the construction site on time. BIM is the ideal tool for integrating the various tasks involved in the prefabrication process. Its 3D visualization capacity and information management and communication systems are key features in generating essential synergies (Nawari, 2012).

This paper describes a modular wind turbine made of prefabricated elements, but attention has also been focused on how this prefabrication process can be supported by new information technologies. BIM not only provides 3D visualization of the tower (something which in fact was already possible in the past without implementing BIM methodology), but also handles information management and supplies relevant data to each of the stakeholders when needed. The BIM model contains updated information on the individual project and can be used to check the current status of each of the prefabricated elements, no matter whether they are under production, ready to be shipped or already on site.

The next step of this research project will be the transformation of the BIM model to the project's main source of information for supporting the various manufacturing and on-site placement processes as well as future maintenance activities. 
Further steps to be undertaken in this research project On the one hand, the new design presented in this paper includes already prefabricated elements in order to increase the efficiency. On the other hand, BIM has been proposed as the perfect complement for prefabrication, based on the proven advantages of this methodology. The aim of this research group is to develop a BIM model, which will be the main source of information of the project during the whole life cycle of the turbine. The prefabricated elements can be previously defined and modeled as BIM objects stored in a library for immediate use; in these objects the detailed definition of the elements properties is included. As a further development materials and prefabricated elements logistic planning supported by BIM will be developed.

\section{Conclusions}

In Germany today special focus is being put on the development of renewable energies, especially wind power. The increase in the hub height of wind turbines means that tower structures have to be more massive. This, in turn, leads to higher transport and assembly costs. The present paper describes the design and construction of the hybrid ${ }^{2}$ tower.

Hybrid $^{2}$ towers are currently being developed as part of a research project at the Technische Hochschule Mittelhessen (University of Applied Sciences) in the State of Hesse in Germany together with Oberhessisches Spannbetonwerk $\mathrm{GmbH}$. The mission statement driving the development of the new hybrid ${ }^{2}$ towers for onshore wind turbines is associated with optimizing the performance of the supporting structure. The new tower concept reduces the amount of material used, and thus the weight of the tower itself decreases remarkably. Moreover, hybrid ${ }^{2}$ towers are designed to cut transport and assembly costs dramatically.

Due to the high dynamic loads to which it is exposed, a wind turbine only has a lifetime of some 20 years. The traditional wind turbine is set for reconstruction and there will be widespread repowering. All this means that new and more efficient wind turbines will replace old wind turbines at the same location. Planning and cost estimations with respect to deconstruction and other tasks during the life cycle of a wind turbine will have to be dealt with. This is why good cooperation among stakeholders is so necessary. Such cooperation is facilitated by Building Information Modelling methodology.

However, this is not the only advantage of BIM. The current research aims at implementing BIM methodology from the early design phases, so that the model becomes the centralized source of information. It remains to be said that BIM can enhance prefabrication processes and optimize the performance of a hybrid ${ }^{2}$ tower during its complete life cycle.

\section{Competing interests}

The authors declare that they have no competing interests.

\section{Authors' contributions}

MK and JM carried out the development of the hybrid towers, such as the construction processes, the structural design, assembling and benefits of the hybrid $^{2}$ tower. LA and JD carried out the general inefficiency problems in constructions, the performance improvement techniques and methodologies like BIM and prefabrication as well as the benefits of combining them. The background and conclusions were composed in cooperation. All authors read and approved the final manuscript.

\section{Acknowledgements}

The hybrid ${ }^{2}$ towers were developed by the Technische Hochschule Mittelhessen* (Giessen, Germany) together with the precast company Oberhessisches Spannbetonwerk (Nidda, Germany). The project (HA project no. 352/12-42) is funded within the framework of the Hessen ModellProjekte, financed with funds from LOEWE (Landes-Offensive zur Entwicklung Wissenschaftlich-ökonomischer Exzellenz ${ }^{* *}$, Förderlinie 3: KMU-Verbundvorhaben).

* University of Applied Sciences

** State Offensive for the Development of Scientific and Economic Excellence

Received: 20 August 2015 Accepted: 29 December 2015

Published online: 08 January 2016

\section{References}

Committee on Advancing the Competitiveness and Productivity of the U.S. Construction Industry, National Research Council (2009). Advancing the Competitiveness and Efficiency of the U.S. construction Industry. http://www. nap.edu/catalog/12717.html. Accessed 12 May 2015.

Dawood, N., Akinsola, A., \& Hobbs, B. (2002). Development of automated communication of system for managing site information using internet technology. Automation in Construction, 11(5), 557-572.

Eastman, C., Teicholz, P., Sacks, R., \& Liston, K. (2011). A Guide to Building Information Modeling for Owners, Managers, Designers, Engineers, and Contractors (2nd ed., pp. 15-44). New Jersey: John Wiley \& Sons, Inc. Hoboken.

Fraunhofer IWES. (2013). Windenergie Report Deutschland 2013. Retrieved from website: http://www.iwes.fraunhofer.de/.

Gasch, R., Twele, J. (2007). Windkraftanlagen: Grundlagen, Entwurf, Planung und Betrieb (5th Edition). B.G. Teubner Verlag, Germany. ISBN: 978-3-8351-0136-4 (pp. 98-118)

Hau, E. (2014). Windkraftanlagen: Grundlagen, Technik, Einsatz, Wirtschaftlichkeit (5th Edition). Springer-Verlag Berlin Heidelberg, Germany. doi: 10.1007/978-3642-28877-7_12

Hu, W., \& Zhou, M. (2009). An integrated and comprehensive information management model for construction project lifecycle (Proceedings - International Conference on Management and Service Science, MASS 2009). doi:10.1109/ ICMSS.2009.5301366.

Liebherr-Werk Ehringen GmbH Germany. (2014). Technical Data, Crawler Crane and Mobile Crane. Retrieved from website: http://www.liebherr.com/de/deu/ produkte/mobil-und-raupenkrane/mobil-und-raupenkrane.html.

McGraw Hill Construction. (2011). Prefabrication and Modularization: Increasing Productivity in the Construction Industry. http://construction.com/market_ research/. Accessed 15 Sept 2014.

Mohd Nawi, M. N., Baluch, N., \& Bahauddin, A. Y. (2014). Impact of fragmentation issue in construction industry: An overview. In MATEC Web of Conferences (Vol. 15, p. 01009). doi:10.1051/matecconf/20141501009.

Nawari, N. O. (2012). BIM standard in off-site construction. Journal of Architectural Engineering, 18(2), 107-113.

doi:10.1186/s40327-015-0032-4

Cite this article as: Alvarez-Anton et al: Optimization of a hybrid tower for onshore wind turbines by Building Information Modeling and prefabrication techniques. Visualization in Engineering 2016 3: 